Case Report

\title{
Hyper IgE syndrome (hies; job syndrome): A case report
}

\author{
Priyanka Ameta ${ }^{1}$, Anuj Dhyani ${ }^{2}$, Vignesh Hebri Nayak ${ }^{3}$ \& Suresh Goyal ${ }^{4}$ \\ ${ }^{1}$ Senior Resident, ${ }^{2}$ Third Year Resident, ${ }^{4}$ Professor and HOD, Department of Pediatrics, \\ R.N.T. Medical College, Udaipur, ${ }^{3}$ Senior Resident, Department of Pediatrics, \\ K.S. Hegde Medical Academy, Nitte University, Mangalore.
}

\section{Correspondence \\ Priyanka Ameta}

30, Samta Nagar, Hiranmagri, Sector-3, Udaipur, Rajasthan - 313002.

Mobile :+918764072927 E-mail : priyankaameta1985@gmail.com

\begin{abstract}
The hyper-immunoglobulin E syndrome (HIES) is a rare primary immunodeficiency disorder characterized by high serum levels of immunoglobulin E (IgE), recurrent cutaneous and pulmonary infections, chronic dermatitis and a variety of connective tissue and skeletal abnormalities. These patients share characteristic facial appearance and many oral manifestations. We report a case of hyper IgE syndrome (HIES) also known as "Job syndrome".
\end{abstract}

Keywords: Hyper-immunoglobulin E syndrome, Job syndrome, Primary immunodeficiency, Eosinophilia, Recurrent infections.

\section{Introduction}

The hyper-immunoglobulin E syndrome (HIES) is a rare primary immunodeficiency disorder characterized by recurrent cutaneous and pulmonary infections, eczematous dermatitis and elevated serum IgE concentrations $^{1-3}$. In 1966, Davis et al described this disease first as "Job's syndrome" in two girls suffering from recurrent "cold" staphylococcal abscesses, pneumonia and neonatal-onset eczematous rash ${ }^{4}$. In 1972, Buckley et al. ${ }^{5}$ found extremely high serum IgE levels in these patients. Subsequently, other manifestations of the disease have been established, like skeletal, connective tissue, cardiac, and brain abnormalities ${ }^{6-8}$.

Two forms of HIES are recognized: autosomal dominant and autosomal recessive. However, most cases of HIES are sporadic $^{9,10,16}$. Diagnosis in young children can be challenging as symptoms accumulate over a period of time along with confounding clinical dilemmas.

\begin{tabular}{|c|}
\hline Access this article online \\
\hline Quick Response Code \\
\hline
\end{tabular}

\section{Case Report}

A 4 month old female child with failure to thrive and global developmental delay, got admitted to the hospital with complaints of dry and scaly skin for last two months, chest wall abscess and refusal to feed for last three days. No history of fever, cough or shortness of breath. The child was hospitalised one month back for similar history of abscess over the neck and scalp, which grew staphylococcus aureus on culture and was treated with antibiotics and abscess was drained. Her birth history was uneventful. She was delivered to a 24 year old mother (P2L2) via vaginal delivery at 38 weeks with birth weight of $2.37 \mathrm{~kg}$, with an uneventful neonatal period. The child was on breast feeding supplemented with formula feeds and had received only first dose of hepatitis $B$ vaccine at birth.

On the day of admission, her vitals were stable, she was cachexic, had eczematous dermatitis, craniosynostosis, facial dysmorphism, cervical and axillary lymphadenopathy of $1 \mathrm{~cm}$ each and a chest wall abscess measuring $4 * 4 \mathrm{~cm}$ over left anterior chest with no signs of inflammation. Her labs on day of admission, CBC was normal with moderate eosinophilia (AEC-2600, 14\%), chest wall abscess grew coagulase positive staphylococcus aureus. CSF was normal and blood culture was negative.

Her abscess was drained and treated with injectable amoxicillin clavulanic acid, according to bacterial sensitivity pattern. However, the child's condition worsened on D4, she developed respiratory distress and chest $x$-ray showed right upper lobe pneumonia. 
Antibiotics were upgraded and in view of septicaemia, Ivlg was given. After initial improvement, her respiratory distress continued to worsen on D7, when, repeat chest $x$ ray showed features of bilateral pneumatoceles with pneumothorax. Intercostal chest tubes were put, and antifungal drugs were added as she was worsening further. Despite our best efforts, the child expired on day 10.
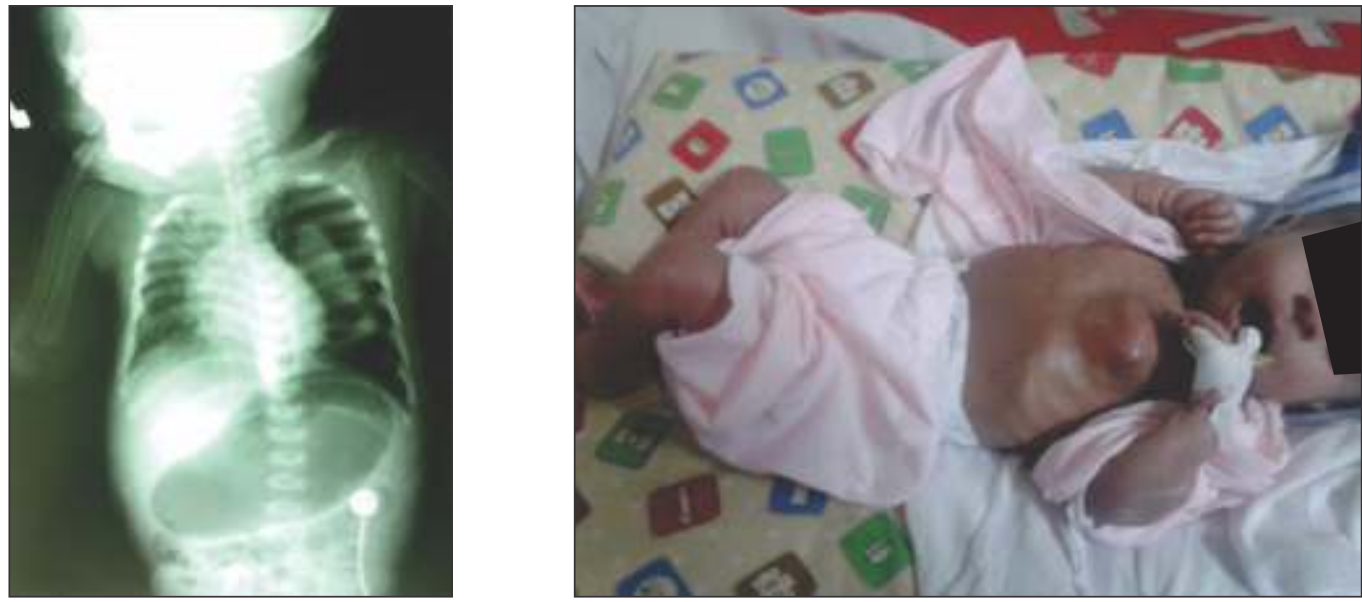

Figure $\mathbf{1}$ (left) : Chest $X$ ray showing pneumatocoele and left pneumothorax; Figure $\mathbf{2}$ (right) : showing patient with facial dysmorphism, eczematous dermatitis and left chest wall abscess. Further laboratory investigations showed low CD 4, low CD3 and very low CD 8 levels, IgE levels were $>2500 \mathrm{IU} / \mathrm{ml}$. Ig A, IgG and IgM levels were within normal range.

\section{Discussion}

Clinical manifestations of HIES: Hyper IgE Syndrome usually presents very early in life. Almost all patients suffer from recurrent staphylococcal infections, beginning in infancy and predominantly involving the skin and lungs ${ }^{1,2,11}$. Newborn pustular and eczematous rashes are usually the first manifestations of the disease, typically affecting the face and scalp, with an eosinophilia and caused by Staphylococcus aureus. Boils are a classic finding ${ }^{6}$. Recurrent pyogenic pneumonias are very common, starting in the childhood.

In these patients, the degree of inflammatory symptoms is variable. The "cold" abscesses, without external signs of inflammation, initially described by Davis and colleagues ${ }^{4}$, are common. Staphylococcus aureus is the bacterium most frequently isolated, but Streptococcus pneumoniae, Haemophilus influenzae, enteric Gram-negative bacteria; Candida and Aspergillus are also common. Pneumonia is frequently followed by pneumatocele or bronchiectasis, which are commonly superinfected by Aspergillus fumigatus and Pseudomonas aeruginosa ${ }^{12,13}$. Several cases of pneumocystosis, cryptococcosis, histoplasmosis and candidiasis have also been reported.

The facial appearance is very characteristic: facial asymmetry, prominent forehead, deep-set eyes, broad nasal bridge, mild prognathism, and rough appearance of the facial skin with prominent pores. Some individuals retain their primary teeth, because of the failure of those teeth to exfoliate. Other features are craniosynostosis, multiple fractures, scoliosis, Chairi I malformation, central depressions in the tongue and high arch of the palate ${ }^{6,14,15}$.

Laboratory investigations: Serum IgE concentrations are extremely high in patients with HIES (> $2000 \mathrm{IU} / \mathrm{ml}$ ). The molecular mechanism of hyper-lgE is unclear $^{3,13}$. HIES patients have normal or decreased serum IgM, IgG and IgA levels. Eosinophilia is the other consistent laboratory finding ${ }^{3}$.Total white blood cell counts are normal but they often fail to elevate appropriately during acute infection. An impaired chemotaxis of neutrophils or monocytes has been described, a defect that explains the "cold abscesses" seen in these patients.

Therapy of hyper-IgE syndrome: There is no cure for HIES yet. The consensus favors long-term prophylactic therapy 
with an anti-staphylococcal antibiotic such as trimethoprim-sulfamethoxazole ${ }^{2}$. The efficacy of antifungal prophylaxis remains unproven. Other options include IFN-gamma, which has inconsistent effects on IgE levels, and, Intravenous immunoglobulin, which may decrease the number of infections for some patients ${ }^{17,18}$.

Bone marrow transplantation has been unsuccessful in this condition.

Our child had many features suggestive of Hyper IgE syndrome; eczema, recurrent staphylococcal abscess

\section{References}

1. Buckley RH. The hyper-IgE syndrome. Clin Rev Allergy Immunol 2001;20:139-154.

2. Grimbacher B, Holland SM, Puck JM. Hyper-IgE syndromes. Immunol Rev 2005;203:244-250.

3. Freeman AF, Holland SM. The hyper-IgE syndromes. ImmunolAllergy Clin North Am 2008;28:277-291.

4. Davis SD, Schaller J, Wedgwood RJ. Job's Syndrome. Recurrent, "cold", staphylococcal abscesses. Lancet, 1966;1(7445):1013-1015.

5. Buckley RH, Wray BB, Belmaker EZ. Extreme hyperimmunoglobulinemia $E$ and undue susceptibility to infection. Pediatrics 1972;49:59-70.

6. Grimbacher B, Holland SM, Gallin JI, Greenberg F, Hill SC, Malech HL, Miller JA, O'Connell AC, Puck JM. Hyper-IgE syndrome with recurrent infections--an autosomal dominant multisystem disorder. N Engl J Med 1999;340:692-702.

7. Freeman AF, Collura-Burke CJ, Patronas NJ, Ilcus LS, Darnell D, Davis J, Puck JM, Holland SM. Brain abnormalities in patients with hyperimmunoglobulin E syndrome. Pediatrics 2007;119:1121-1125.

8. Ling JC, Freeman AF, Gharib AM, Arai AE, Lederman RJ, Rosing DR, Holland SM. Coronary artery aneurysms in patients with hyper IgE recurrent infection syndrome. ClinImmunol 2007;122:255-258.

9. Minegishi Y, Saito M, Tsuchiya S, Tsuge I, Takada H, Hara. Dominant Negative mutations in the DNA binding domain of STAT3 causing Hyper IgE syndrome. Nature. 2007; 448(7157):1058-62.

10. Holland SM, DeLeo FR, Elloumi HZ, Hsu AP, Uzel G, Brodsky N. STAT3 mutations in the hyper-IgE syndrome. N Engl J Med; 2007;35:1608 1619. without fever and signs of inflammation, pneumonia complicated with pneumatocoele and pneumothorax, facial dysmorphism, craniosynostosis and elevated eosinophil count and IgE.

\section{Conclusion}

Patients with Hyper IgE syndrome usually die prematurely due to pulmonary infections; early diagnosis with treatment and prophylactic therapy with co-trimoxazole can be lifesaving and can lead to a significant reduction in morbidity.

11. Grimbacher B, Schäffer AA, Holland SM, Davis J, Gallin JI, Malech HL, Atkinson TP, Belohradsky BH, Buckley RH, Cossu F, Español T, Garty BZ, Matamoros N, Myers LA, Nelson RP, Ochs HD, Renner ED, Wellinghausen N, Puck JM. Genetic linkage of hyper-IgE syndrome to chromosome 4. Am J Hum Genet 1999, 65:735-44.

12. Freeman AF, Kleiner DE, Nadiminti H, Davis J, Quezado M, Anderson V, Puck JM, Holland SM. Causes of death in hyper-IgE syndrome. J Allergy ClinImmunol 2007;119:1234-1240.

13. Minegishi Y. Hyper-IgE syndrome. CurrOpinlmmunol 2009;21:487492.

14. Domingo DL, Freeman AF, Davis J, Puck JM, Tianxia W, Holland SM, Hart TC. Novel intraoral phenotypes in hyperimmunoglobulin-E syndrome. Oral Dis 2008;14:73-81.

15. Borges WG, Hensley T, Carey JC, Petrak BA, Hill HR. The face of Job. Pediatr 1998;133:303-305.

16. Renner ED, Puck JM, Holland SM, Schmitt M, Weiss M, Frosch M, Bergmann M, Davis J, Belohradsky BH, Grimbacher B. Autosomal recessive hyperimmunoglobulin $\mathrm{E}$ syndrome: a distinct disease entity. J Pediatr 2004;144:93-99.

17. Kimata $\mathrm{H}$. High-dose intravenous gamma-globulin treatment for hyperimmunoglobulinemia E syndrome. J Allergy ClinImmuno 1995;95:771-774.

18. Bilora F, Petrobelli F, Boccioletti V, Pomerri F. Moderate-dose intravenous immunoglobulin treatment of Job's syndrome. Case report. Minerva Med 2000;91:113-116 